\title{
O Direito Fundamental à Greve e as Condutas Antigrevistas do Empregador
}

\author{
Lucas Antônio Bueno \\ Graduado pela Faculdade Pitágoras de Divinópolis/MG. \\ Pós-Graduado em Direito e Processo do Trabalho pela \\ Universidade Anhanguera/Uniderp. Pós-graduado em \\ Direito Constitucional pela Universidade Anhanguera/ \\ Uniderp. Mestrando em Direito em "Proteção dos Direitos \\ Fundamentais" pela Universidade de Itaúna/MG. Iukasbue- \\ nos@hotmail.com
}

\section{RESUMO}

0 presente texto trata do direito fundamental de greve e das condutas antigrevistas que o empregador pode criar como obstáculo à efetivação deste direito fundamental. 0 direito de greve no Brasil foi conquistado por meio de intensas lutas dos trabalhadores e sindicatos ao longo da história recente brasileira. Esse direito passou por três estágios de natureza jurídica, a saber: a greve como um delito, como uma liberdade e como um direito fundamental do trabalhador entendido como um ente coletivo. Ente coletivo no sentido de contraposição ao ser individual trabalhador. Quando este adere a seus pares na defesa de um interesse comum nasce um ser autônomo do ser individual trabalhador, o ser coletivo, exemplificado pelas agremiações de trabalhadores que autonomamente possuem direito além daqueles elencados para o individual. Não obstante atualmente a greve ser um direito constitucionalmente assegurado, há diversas condutas do empregador que lesam de morte este direito fundamental. Essas condutas são chamadas pelo neologismo de condutas antigrevistas em alusão às condutas antissindicais bastante estudadas no âmbito da Organização Internacional do Trabalho (OIT). Tais condutas podem se dar de forma expressa, a exemplo da ameaça de demissão individual ou em massa, ou podem ocorrer de forma velada, mediante condutas que causam um temor ao empregado grevista de sofrer qualquer espécie de retaliação. No ordenamento jurídico pátrio, bem como na jurisprudência e literatura especializada (doutrina) muito pouco se tem debatido sobre 0 assunto, tal como caracterizar uma conduta antigrevista, como preveni-la e repará-la, além de como 0 judiciário poderá atuar no combate a tais condutas. Não obstante este direito ser de baixa densidade normativa, sempre se poderá buscar o judiciário, pelo princípio da inafastabilidade da jurisdição, por meio das ações de obrigação de fazer, não fazer e mais ainda pelas reparações na qualidade de indenizações por dano material e moral. Na elaboração do presente artigo foi utilizado essencialmente um estudo bibliográfico revisando a literatura sobre o tema, bem como a legislação pátria e internacional que trata sobre 0 direito de greve, em uma abordagem crítica, desconstrutiva e reconstrutiva. Para tanto, adota-se um raciocínio dedutivo partindo do histórico do direito de greve, 
das normas internas e internacionais sobre o tema, da caracterização e conceituação das condutas antissindicais, dos direitos fundamentais, para uma análise da realidade brasileira do direito de greve e os obstáculos impostos pelo empregador na efetivação deste direito fundamental, as condutas antigrevistas, e como preveni-las ou cessá-las por meio das obrigações de fazer e não fazer e repará-las mediante as obrigações compensatórias e ressarcitórias, bem como pelo dano moral coletivo.

Palavras-chave: Greve. Direitos fundamentais. Condutas antigrevistas.

\title{
The Fundamental Right to Strike and the Anti-Strike Conduct of the Employer
}

\begin{abstract}
This paper deals with the fundamental right to strike and the anti-strike types of conduct that employers can pose as obstacles to the realization of this fundamental right. The right to strike in Brazil has been achieved through strong struggles of workers and unions throughout recent Brazilian history. The right to strike has gone through three legal stages, namely the strike as a criminal offense, as freedom and as a fundamental right of the citizen understood as a collective entity. A collective entity in the sense of contraposition to the individual worker; when such worker joins his peers in defense of a common interest an autonomous being from the individual worker is born: the collective being exemplified by associations of workers that autonomously have rights beyond those listed for the individual. Although today the right to strike is constitutionally guaranteed, there are several employers' types of behavior that injure this fundamental right mortally. These types of behavior are called by the neologism the anti-strike conduct in reference to the anti-union conduct widely studied within the International Labor Organization (ILO). Such types of conduct can be explicit, for example, a threat of individual or mass dismissal, or can be covert through behavior that incites, in a striker, fear of undergoing any sort of retaliation. In the national legal system, jurisprudence and doctrine very little has been discussed about this topic. There is little discussion on how to characterize anti-strike conduct, how to prevent it and repair it and even how the judiciary may act to combat such conduct. Although this right is of low normative density, it is always possible to seek the judiciary through the legal principle of non-obviation of jurisdiction through actions of obligation to do, not to do and even actions for compensation for material and moral damage. To produce this paper, a bibliographic study reviewing the literature on the subject was essentially used. National and international laws which deal with the right to strike in a critical, deconstructive and reconstructive approach were also reviewed. To this end, I have adopted deductive reasoning starting from: the history of the right to strike; the domestic and international rules on the subject; the characterization and conceptualization of anti-union conduct; fundamental rights for an analysis of the Brazilian reality regarding the right to strike and obstacles imposed by employers to the realization of this fundamental right; anti-strike types of conduct, and how to prevent them or terminate them through obligations to do and not to do and repair them through compensatory and reparatory obligations, as well as through collective moral damage.
\end{abstract}

Keywords: Strike. Fundamental rights. Anti-strike conduct.

\section{Sumário}

1 Introdução. 2 Conceito de Greve e sua Matriz de Direito Fundamental. 2.1 Conceito de Greve. 2.2 História do Direito de Greve no Brasil e Evolução Jurídica. 2.3 0 Direito de Greve como Direito Fundamental. 3 Condutas Antigrevistas do Empregador. 3.1 Conceito de Condutas Antigrevistas. 3.2 Caracterização, Reparação e Prevenção: Atuação Judicial no Combate às Condutas Antigrevistas. 3.3 0 Dano Moral Coletivo em Decorrência das Condutas Antigrevistas. 4 Considerações Finais. 5 Referências. 


\section{INTRODUÇÃO}

Este estudo aborda a questão do direito fundamental de greve e dos atos do empregador que lesam tal direito, denominados condutas antigrevistas. Esse direito é garantido pela Constituição da República (CR) e pela Lei de Greve, lei 7.783/89, mas que encontra na prática óbices à sua efetiva concretização.

Neste sentido investiga-se como e quais condutas do empregador podem, de forma expressa ou velada, criar embaraços ou obstaculizar o direito fundamental à greve.

No tocante aos objetivos específicos pretende-se analisar o conceito de greve; estudar como o direito de greve foi elevado ao patamar de direito fundamental; verificar quais condutas do empregador poderão ser consideradas antigrevistas; demonstrar as consequências destas condutas no âmbito da atuação paredista; pesquisar a atuação da Justiça do Trabalho ante tais condutas dos empregadores; analisar a possibilidade de utilização das ações coletivas no sentido da persecução da indenização pelo dano moral, pelo ato ilícito das condutas antigrevistas dos empregadores.

Justifica-se a escolha do tema pela relevância prática do assunto na atuação da atividade sindical, da Justiça do Trabalho nos dissídios de greve, na conduta desta Justiça especializada acerca das indenizações coletivas pelo ato abusivo perante os trabalhadores que realizarem o movimento paredista, na atuação legislativa do congresso brasileiro na atividade legiferante para coibir as condutas antigrevistas do empregador. Justifica-se igualmente a escolha do tema pela relevância teórica perante a comunidade científica e acadêmica no aperfeiçoamento dos estudos sobre o assunto.

Destarte, pretende-se compreender como as condutas do empregador podem lesar o direito ao livre exercício de greve constitucionalmente assegurado e como o judiciário pode ser utilizado para combater estas condutas. 
Nesse sentido, tentar-se-á se responder a questionamentos tais como: Qual o conceito de greve? O direito de greve pode ser considerado um direito fundamental? O que são condutas antigrevistas e como caracterizá-las, repará-las e preveni-las? Como o poder judiciário pode atuar combatendo tais atos? É possível acessar o judiciário por meio das ações coletivas pleiteando a indenização pelo dano moral diante das condutas antigrevistas?

Para tanto, será adotada neste trabalho uma investigação de cunho teórico-bibliográfico partindo de uma concepção geral do que seja o direito de greve, atos antissindicais, direitos fundamentais para uma concepção específica do que sejam condutas antigrevistas e suas consequências no âmbito do movimento paredista brasileiro.

Neste sentido, é de suma importância um estudo acerca da Sociologia, da História do Direito, do Direito Constitucional, e da Lei de Greve para uma análise mais completa e detalhada do assunto.

O trabalho é composto de duas partes: na primeira discute-se o conceito de greve e sua natureza de direito fundamental, para então, na segunda parte analisar o que de fato venham a ser condutas antigrevistas, quais suas consequências no mundo do direito coletivo do trabalho para os sindicatos e trabalhadores e quais as sanções para os agentes ativos destas condutas, os empregadores e tomadores de serviço.

\section{CONCEITO DE GREVE E SUA MATRIZ DE DIREITO FUNDAMENTAL}

\subsection{Conceito de greve}

A conceituação do direito de greve ao contrário de muitos institutos no direito, não causa muitas interpretações diversas, havendo certa unanimidade na literatura pátria e até mesmo na literatura estrangeira. 
A literatura especializada nacional define greve como sendo a cessação coletiva do trabalho por parte dos trabalhadores, para reivindicarem melhores salários ou condições de trabalho, sendo certo que todas as definições apresentadas, com poucas variações, voltam-se para estas mesmas bases.

Nascimento, em estudo sobre o tema, apresenta diversos conceitos de greve extraídos da literatura internacional, e neles há grande semelhança, como se observa da transcrição abaixo:

Há, na doutrina, diversas conceituações de greve.

Para Gerhard Boldt, é a interrupção coletiva e combinada do trabalho por certo número de trabalhadores da mesma profissão ou empresa, tendo um objetivo de luta, a fim de que seus fins venham a ser atingidos [...].

Rivero e Savatier formulam a seguinte definição: “A greve é a cessação ajustada do trabalho pelos assalariados, para constranger o empregador, através deste meio de pressão, a aceitar seus pontos de vista sobre a questão que é objeto do litígio".

Alfredo J. Ruprecht inclui na sua longa definição, como um dos seus componentes, o seu fim, "exercer pressão sobre o patrão, com o fim de obter o reconhecimento de uma prestação de caráter profissional ou econômico [...]" (Nascimento, 2001, p. 893-894).

Observa-se que nas diversas conceituações apresentadas pelo autor todas apresentam requisitos característicos idênticos, quais sejam: cessação coletiva do trabalho, finalidade de exercer pressão sobre o empregador e busca de melhores condições de trabalho e/ou melhores salários.

Neste sentido, igualmente, é o conceito apresentado por Martins (2007, p. 846), que busca na legislação de greve seu conceito, para o qual "a greve é considerada, em nossa legislação, como a suspensão coletiva, temporária e pacífica, total ou parcial, de prestação pessoal de serviços a empregador (art. $2^{\circ}$. da lei no ${ }^{\circ}$.7.783/89)”. 
Para este autor a conceituação da greve é essencialmente legal, buscada na legislação positivada.

É por meio deste marco legal que se conceituará a greve no presente trabalho. A lei 7.783/89, que dispõe sobre o exercício do direito de greve e dá outras providências, dispõe em seu artigo $2^{\circ}$. que "para os fins desta lei, considera-se legítimo exercício direito de greve a suspensão coletiva, temporária e pacífica, total ou parcial, de prestação pessoal de serviços a empregador”.

Do conceito legal de greve, já bastante lembrado pela literatura internacional e nacional, inclusive antes da edição da mencionada lei, pode-se retirar os seguintes requisitos. A suspensão do trabalho deve ser coletiva, vale dizer, de toda a categoria, ou empresa ou ainda de parte da mesma, como seções ou setor. Impende destacar que a cessação individual do trabalho não configura a greve (exceto na condição de greve ambiental conforme destaca Raimundo Simão de Melo), poderá no caso configurar abandono de emprego, constituindo falta grave suscetível de ensejar a despedida por justa causa do empregado.

Deve ainda a suspensão do trabalho ser temporária e não definitiva, posto que a cessação definitiva caracterizará abandono de emprego, punível como falta grave.

É verdade ainda que a paralisação deve ser pacífica, sem violência a pessoas ou a qualquer bem ou direito de outrem.

Como característica também que se abstrai do conceito legal, é que a greve pode ser total de toda uma categoria ou empresa ou parcial, de uma só seção ou setor da organização. 
Importante ainda destacar que o conceito legal de greve afirma que a paralisação deve ser em face de empregador, nada mencionando acerca dos tomadores de serviço lato senso, que utilizam de trabalhadores sem vínculo empregatício, tais como os profissionais liberais, autônomos, avulsos, dentre outros.

Há que observar que a Lei de Greve foi editada antes da Emenda Constitucional (EC) 45/04, que alterou a competência da Justiça do Trabalho, passando esta a ser competente para o julgamento de causas que envolvam relações de trabalho e não apenas relação de emprego.

Logicamente que a mencionada emenda não alterou o direito material do trabalho para que se dê uma interpretação para que a expressão serviços a empregador seja entendida como serviços a tomador, contudo a partir desta Emenda à Constituição, o ordenamento trabalhista mostra-se aberto à defesa dos direitos de todos os trabalhadores e não somente dos empregados. Assim, em uma interpretação conforme a constituição e pela aplicabilidade máxima das normas constitucionais, deve atualmente ser entendido que o direito de greve pode ser exercido não só pelos trabalhadores com vínculo empregatício, mas sim pelos trabalhadores de todas as modalidades, ainda que sem vínculo de emprego, pois não poderá uma norma infraconstitucional restringir um direito fundamental assegurado pela Constituição, tal como o direito de greve, pois a CR disciplina que é assegurado o direito de greve aos trabalhadores, sem diferenciar se possuem ou não vínculo empregatício. Destarte, não se poderá aceitar qualquer interpretação que atribua apenas aos empregados, àqueles que têm vínculo de emprego, o direito de greve, sob pena de interpretação neste sentido ser restritiva e tachada de flagrante inconstitucionalidade.

No âmbito constitucional o artigo $9^{\circ}$ da CR é enfático ao asseverar que "é assegurado o direito de greve, competindo aos trabalhadores decidir sobre a oportunidade de exercê-lo e sobre os interesses que devam por meio dele defender" (destaque do autor deste artigo). Neste diapasão, a 
Constituição assegurou o direito de greve aos trabalhadores de um modo geral e não somente aos empregados. Assim, a qualquer parcela de trabalhadores é lícito iniciar uma greve e não somente aos que têm vínculo de emprego formal.

A greve, antes mesmo de ser um fenômeno jurídico, deve ser conceituada como um fenômeno social, pois ainda que o direito não amparasse este instituto ele existiria socialmente como produto da luta de classe, portanto ela deve ser entendida também na acepção sociológica, ainda que este texto atenha-se apenas a sua faceta jurídica.

Neste sentido, poderia citar como exemplos de greve no sentido social, a greve de fome, todavia esta não tem amparo jurídico sendo, destarte, inservível à análise do direito.

Neste diapasão, a greve pode ser conceituada, conforme antes exaustivamente demonstrado mutatis mutandis, como o fato social e jurídico em que os trabalhadores coletivamente cessam a prestação de serviços aos tomadores de forma temporária e pacífica, total ou parcialmente, no sentido pressioná-los na busca de melhores condições de trabalho ou melhores salários.

\subsection{História do direito de greve no Brasil e evolução jurídica}

O direito de greve no Brasil não seguiu uma sequência cronológica de acontecimentos de conquista desse direito. No Brasil o direito de greve ora era uma liberdade, ora um delito e por fim um direito fundamental.

A primeira vez que a legislação pátria tratou da greve, segundo Delgado (2006, p. 1.319-1.321), foi no Código Penal de 1890, em que criminalizava o instituto e qualquer conduta paredista. Logo em seguida, em $12 / 12 / 1890$, o decreto 1.162 descriminalizou a greve e apenas os atos de 
ameaça, constrangimento ou violência cometidos durante a mesma eram punidos como ilícito penal. Nesse período observa-se claramente a greve como um delito e após como uma liberdade, ainda que mitigada.

A Constituição de 1934 nada mencionou sobre a greve e a que se seguiu, em 1937, mencionou acerca deste instituto "criminalizando-a" novamente no artigo 139, disciplinando que considerava "a greve e o locaute recursos antissociais, nocivos ao trabalho e ao capital e incompatíveis com os superiores interesses da produção nacional”. Logo em seguida outros diplomas vedaram a greve e a consideraram crime, tais como a Lei de Segurança Nacional, decreto-lei 431 de 1938, decreto 1.237 de 1939, Código Penal de 1940 e Consolidação das Leis do Trabalho (CLT), no artigo 722, aqui quanto à greve dos empregadores, denominada locaute.

A primeira norma efetivamente a tratar da greve foi o decreto-lei 9.070 de 1946 que definiu a greve e a permitiu nas atividades acessórias. A Constituição de 1946 confirmou o instituto como um verdadeiro direito trabalhista. Não obstante a Constituição de 1946 assegurar o direito à greve, este ainda estava bastante restrito pelo decreto 9.070 , editado no mesmo ano.

Com a ascensão do regime militar ao poder em 1964, o direito de greve foi rigidamente restringido, pois mais que um direito era também um fato social capaz de subverter o regime imposto naquele momento. Além do mais, a greve poderia ter a conotação política de descontentamento com o regime.

No próprio ano de 1964 foi editada a lei 4.330 que tratava do direito de greve que, além de restringi-la, vedava a ocupação dos estabelecimentos por parte dos grevistas. A Constituição de 1967 restringiu mais ainda o direito de greve, proibindo-a nos serviços públicos e atividades essenciais. Com o Ato Institucional $\mathrm{n}^{\mathrm{o}} .5 \mathrm{o}$ direito à greve ficou quase que totalmente inviabilizado pelo grande cerceamento imposto a este direito. 
Nos anos que se seguiram até 1988, o direito de greve ficou quase que suspenso, haja vista que qualquer manifestação sindical neste sentido era duramente reprimida pelo regime autoritário, conforme ocorreu com as greves do ABC Paulista em 1978 com a prisão e condenação de diversos sindicalistas, dentre eles Luiz Inácio Lula da Silva, o Lula. Cabe destacar ainda que, no período das décadas de 1970 e 1980 muitas leis e decretos foram aprovados no sentido de reprimir ainda mais qualquer movimento paredista.

Finalmente a CR de 1988 estabeleceu o direito de greve como verdadeiro direito fundamental do ser humano, constituindo-se este o momento mais notável de afirmação do direito de greve na história da legislação brasileira. Ademais, para sacramentá-lo, foi editada a lei 7.783/89, que estabeleceu de forma pormenorizada a efetivação e aplicação desse direito.

Não obstante a afirmação do direito de greve como direito constitucionalmente assegurado, muito ainda falta fazer por este direito, como a alteração da legislação para inserir a permissão expressa do direito de greve aos trabalhadores sem vínculo empregatício, além da efetivação do direito de greve dos funcionários públicos que, não obstante haver previsão expressa na $\mathrm{CR}$, na prática o seu direito está inviabilizado (apesar da mudança com o julgamento do Mandado de Injunção 712-8 julgado pelo Supremo Tribunal Federal).

Neste diapasão o direito de greve, como todo o direito, ainda está em movimento, não findando a sua história com a Constituição de 1988 e com a lei 7.783/89.

\subsection{O direito de greve como direito fundamental}

Com a edição da Constituição de 1988, o direito de greve foi elevado a direito fundamental do ser humano, entendido este no sentido coletivo. 
O direito de greve está descrito no artigo $9^{\circ}$ da $\mathrm{CR}$ asseverando que "é assegurado o direito de greve, competindo aos trabalhadores decidir sobre a oportunidade de exercê-lo e sobre os interesses que devam por meio dele defender".

Impende observar que o artigo 9ำ está inserido no Capítulo II "Dos Direitos Sociais”, que por sua vez encontra-se dentro do título maior II "Dos Direitos e Garantias Fundamentais".

$\mathrm{Na}$ ordem internacional não existe uma convenção que estabeleça especificamente sobre o direito de greve ou que o estabeleça como um direito fundamental, todavia a Organização Internacional do Trabalho (OIT), pela Convenção 98, estabelece os princípios sobre o direito de organização e negociação coletiva e em seu artigo $1^{\circ}$. 2 "a" disciplina que a proteção deverá ser destinada à vedação da dispensa arbitrária por qualquer empregado que participe de ato sindical, e dentre eles logicamente encontra-se a greve.

É verdade que não está estampada nesta convenção seu caráter de direito fundamental, todavia sua fundamentalidade extrai-se da interpretação.

Neste diapasão, como a Convenção 98 da OIT foi ratificada pelo Brasil, fazendo parte do ordenamento jurídico e o direito de greve constar do texto expresso da CR no título dos direitos e garantias fundamentais, $\mathrm{e}$ pela recepção de outras normas de direitos fundamentais decorrentes de tratados que a CR permite em seu artigo $5^{\circ} \S 2^{\circ}$, o direito de greve alcança a expressão de direito fundamental do ser humano. Neste sentido, acerca dos direitos fundamentais Santos assevera que:

Direitos fundamentais seriam aqueles direitos, espécies do gênero direitos humanos, que em determinado momento histórico, político, cultural, e social de um povo, este resolveu positivá-los no ordenamento jurídico, sobretudo na Carta Magna, ou seja, na Constituição Federal (Santos, 2008, p. 277). 
Neste sentido ainda é a lição de Sarlet (2006, p. 35) ao disciplinar que os “direitos fundamentais' se aplicam para aqueles direitos do ser humano, reconhecidos e positivados na esfera do direito constitucional positivo de determinado Estado".

Desta feita, com a positivação do direito de greve na Constituição de 1988 no título dos direitos e garantias fundamentais e pela lei 7.783/89, este se afirmou como um direito fundamental.

Neste sentido assevera o professor João Humberto Cesário:

De todo o estudado até aqui, devo sublinhar, em virtude da importância desta conclusão para o avanço do estudo que vem sendo desenvolvido, que a greve e a negociação coletiva são direitos fundamentais dos trabalhadores, sendo consagrados no plano externo pelos regramentos jurídicos internacionais e no interno pela Constituição da República (Cesário, 2007, p. 5).

Neste mesmo sentido é o entendimento de Delgado (2006, p. 1.315), em clara assertiva, ao mencionar que "a natureza jurídica da greve, hoje, é de um direito fundamental de caráter coletivo, resultante da autonomia privada coletiva inerente às sociedades democráticas”.

Ainda neste sentido, Nascimento defende que a greve:

é um direito básico do trabalhador, tão relevante, no plano coletivo, como os principais direitos fundamentais da pessoa, no nível individual. Trata-se, portanto, de um direito fundamental do homem social, competindo aos trabalhadores decidir sobre a oportunidade de exercê-lo e sobre os interesses que devam por meio dele defender (Nascimento, 1989, p. 26).

Nesta mesma linha, Silva afirma:

A greve não é um simples direito fundamental dos trabalhadores, mas um direito fundamental de natureza instrumental e desse modo se insere no conceito de garantia constitucional, porque funciona como 
meio posto pela Constituição à disposição dos trabalhadores, não como bem auferível em si, mas como um recurso de última instância para a concretização de seus direitos e interesses (Silva, 1989, p. 269).

No âmbito internacional como direito de suma importância, o direito de greve ganhou reconhecimento pelo Comitê de Liberdade Sindical e Comissão de Peritos, que estabeleceu regras e princípios básicos em matéria de greve, e como primeiro princípio expressou que "a greve é um direito fundamental de que devem gozar os trabalhadores e organizações respectivas, desde que seu exercício se revista de caráter pacífico”.

Nesse contexto, o direito de greve alcançou o patamar de verdadeiro direito fundamental exercido democraticamente e pacificamente na busca dos interesses da classe trabalhadora.

\section{CONDUTAS ANTIGREVISTAS DO EMPREGADOR}

\subsection{Conceito de conduta antigrevista}

Não há nos estudos efetivados acerca do direito de greve um conceito pronto do que sejam condutas antigrevistas. Por certo que o tema tem sido pouco debatido pelos especialistas da área, o que impõe uma conceituação por analogia do que seriam condutas antissindicais, haja vista que as condutas antissindicais são gênero das quais as condutas antigrevistas são espécies. Assim, deve-se partir da visão do conceito de condutas antissindicais para traçar um conceito do que seriam condutas antigrevistas, haja vista sua baixa densidade normativa e pela omissão do tema na doutrina e jurisprudência pátrias.

A convenção 98 da OIT trata sobre a proteção contra os atos antissindicais e no seu artigo $1^{\circ}$ estabelece que: 
1 - Os trabalhadores gozarão de adequada proteção contra atos de discriminação com relação a seu emprego.

2 - Esta proteção aplicar-se-á especialmente a atos que visem: [...]

b) causar demissão de um trabalhador ou prejudicá-lo de outra maneira por sua filiação a um sindicato ou por sua participação em atividades sindicais fora das horas de trabalho ou, com o consentimento do empregador, durante o horário de trabalho (Organização..., 2014a, destaques do autor deste artigo).

Neste diapasão pode-se afirmar que as condutas antigrevistas, encaixam-se no conceito do gênero condutas antissindicais ao mencionar sobre a proteção contra a "participação em atividades sindicais". Ora, com toda certeza a greve é por excelência uma das mais sublimes atividades sindicais.

Continuando, neste sentido Uriarte conceitua os atos antissindicais como sendo:

aqueles que prejudiquem indevidamente um titular de direitos sindicais no exercício da atividade sindical ou por causa desta ou aqueles atos mediante os quais lhe são negadas, injustificadamente, as facilidades ou prerrogativas necessárias ao normal desempenho da ação coletiva (Uriarte, 1989, p. 10).

A própria lei de greve, ainda que timidamente, traz a ideia do que seja uma conduta antigrevista ao asseverar em seu artigo $6^{\circ} \S 2^{\circ}$ que “é vedado às empresas adotar meios para constranger o empregado ao comparecimento ao trabalho, bem como capazes de frustrar a divulgação do movimento”. É possível afirmar que a lei trouxe exemplos de condutas que divergem do direito fundamental de greve, ao estabelecer a proteção contra os atos de ingerência do empregador no livre direito de greve. 
O texto legal foi tímido e equivocado ao arrolar exemplos de condutas antigrevistas, uma vez que o correto seria conceder a proteção geral aos atos antigrevistas e deixar que o intérprete analisasse no caso concreto a ocorrência destes atos.

Ante o exposto e sob a luz da CR e da Convenção 98 da OIT sobre os atos antissindicais mutatis mutandis poderia se conceituar as condutas antigrevistas como todo ato do tomador de serviços que direta ou indiretamente, de forma velada ou expressa, inviabilize ou embarace, de forma total ou parcial, o livre exercício do direito fundamental à greve.

Desta conceituação pode-se extrair as seguintes características. O sujeito ativo que promove as condutas antigrevistas em um sentido mais amplo é, ao contrário do que diz a Convenção 98 da OIT e o artigo $6^{0}$ da lei de greve, o tomador de serviço e não só as empresas ou empregadores, pois como mencionado anteriormente o direito fundamental de greve pode ser exercido, em uma interpretação conforme a constituição e pela máxima efetividade dos direitos fundamentais, por qualquer trabalhador e não só o empregado, ou seja, os avulsos, profissionais liberais, eventuais, dentre outros.

As condutas poderão ocorrer de forma direta, ou seja, sobre o trabalhador ou sua agremiação, ou de forma indireta na pressão ou qualquer forma de conduta sobre o sindicato profissional ou de algum de seus dirigentes de forma a embaraçar ou boicotar este direito.

Poderá ser de forma explícita, como as ameaças de perda de emprego, ou de forma velada, subliminar, nas condutas efetivadas pelo tomador de serviços que causará uma consequência, ainda que a longo prazo, para o trabalhador. 
Poderá ainda inviabilizar total ou parcialmente o direito de greve, realizando atos que frustrem a manifestação paredista de vez ou embaracem injustificadamente as facilidades e prerrogativas necessárias à realização do movimento.

Implicitamente ainda, pode-se observar que o sujeito passivo das condutas antigrevistas são os trabalhadores individualmente ou o ente coletivo, sindicato, pois estes são os titulares do direito de greve e seus viabilizadores.

Nesse sentido, toda conduta que de qualquer forma seja contrária ao livre exercício do direito de greve e não esteja amparada pela lei, será uma conduta antigrevista, merecendo que seja cessada por meio de mandamento judicial pela inafastabilidade da jurisdição.

As condutas antigrevistas, sob outro ângulo do conceito, poderiam ser conceituadas ainda como um abuso de direito. Assevera o artigo 187 do Código Civil (CC) que "também comete ato ilícito o titular de um direito que, ao exercê-lo, excede manifestamente os limites impostos pelo seu fim econômico ou social, pela boa-fé ou pelos bons costumes”.

O direito de exigir do trabalhador a prestação dos serviços para os quais o empregador o contratou decorre do exercício regular de um direito assegurado pela lei e pelo contrato de trabalho.

Quando, porém, de um movimento paredista, em que a prestação de serviços é suspensa, cabe ao tomador de serviços respeitar outros direitos que se encontram acima da obrigatoriedade da prestação do labor e do exercício regular de seu direito de exigir a prestação de serviços dos contratados, devendo respeitar o direito de greve. Quando assim não o faz e nos termos do conceito antes mencionado, realiza atos que embarace ou inviabilize totalmente o direito fundamental de greve, conduta antigrevista, seu exercício regular do direito se transforma em abuso de direito, pois ao exercê-lo, ao exigir a todo custo a prestação de serviços realizando con- 
dutas antigrevistas, excede manifestamente os fins sociais do seu direito, ato este passível de cessação por obrigações de fazer e não fazer e por indenizações por dano moral coletivo, o que passa a expor.

\subsection{Caracterização, reparação e prevenção: atuação judicial no combate às condutas antigrevistas}

Analisada a conceituação do que sejam condutas antigrevistas, há que se observar sua caracterização e a reparação pelo poder judiciário, bem como as possibilidades de prevenção de tais atos.

A caracterização de uma conduta antigrevista passará lógica e necessariamente pela análise das prerrogativas do direito de greve garantido legal e constitucionalmente e de seus titulares.

As condutas antigrevistas podem efetivar-se de diversas maneiras. Nas palavras de Melo:

É de natureza dos conflitos de trabalho a existência de dissensos entre empregadores e trabalhadores, que muitas vezes não são resolvidos por meio da negociação coletiva. Por isso, o enfrentamento entre as partes pode dar lugar a uma fase de endurecimento e acirramento dos ânimos e resultar em represálias contra dirigentes sindicais, ativistas e demais trabalhadores, especialmente por movimentos grevistas, até mesmo com violação da legislação vigente.

Essas represálias podem consistir em atos discriminatórios, em punições (advertências, suspensões, demissões, com ou sem justa causa), além de outros atos prejudiciais ao emprego, como alijamento de promoções, perseguições, assédio moral, etc. (2009, p. 73).

Nesse sentido, quando o empregador realizar qualquer conduta, como referido, que inviabilize totalmente ou embarace o livre exercício do direito fundamental de greve, caracterizada estará a conduta antigrevista. 
Exemplo de tal fato ocorreu há algum tempo e foi noticiado pelo jornal Gazeta do Oeste na edição de 20/11/2010 a 22/11/2010 na greve dos eletricitários da cidade de Divinópolis/MG, sobre um caso de flagrante conduta antigrevista realizada pela Companhia Energética de Minas Gerais (Cemig), em que o coordenador do sindicato na região, Celso Marcos Primo, assim relatou:

Primo relata que uma demissão de um dos coordenadores da greve agravou a situação grevista. "A Cemig, infelizmente convoca trabalhadores para suas atividades, alguns supervisores ficam ligando, fazendo pressão psicológica para que eles retornem. Na quarta-feira (17), nós tivemos uma surpresa, que a empresa da cidade de Uberlândia entrou na Justiça, pedindo a demissão por justa causa de um trabalhador que por sinal é um dos líderes do movimento, um dos responsáveis pela negociação, um dos que sentam com a empresa para poder negociar, nós temos certeza que isto é perseguição por causa da greve. E isso dificulta, pois ele é um trabalhador correto que não tem no seu histórico nenhuma advertência ou punição, ele trabalha há mais de vinte anos na empresa. Somente porque ele está liderando um movimento pacífico organizado, a empresa não tem o direito de querer demiti-lo" (Rodrigues, 2010, p. 7).

Este relato caracteriza um exemplo de conduta antigrevista em que a empregadora ameaça de demissão os empregados ligando para os mesmos "fazendo pressão psicológica” e acessando o judiciário para tentar demitir um dos líderes do movimento.

Assim, conforme anteriormente mencionado, como a conduta da empregadora está em desacordo com o que prevê a lei de greve em seu artigo $7^{\circ}$ parágrafo único, no qual veda a demissão de funcionários durante o movimento paredista, esta conduta é caracterizada como antigrevista.

Ainda como exemplos de condutas antigrevistas do empregador, pode-se citar a veiculação na imprensa de que o movimento é ilegal, para que a sociedade exerça uma pressão negativa sobre a paralisação, assim 
como a ameaça de demissão em massa, a demissão dos líderes do movimento, a contratação de trabalhadores substitutos para executar as tarefas antes realizadas pelos grevistas, pagamento de horas extraordinárias ou verdadeiros impedimentos dos trabalhadores, que estão trabalhando para garantir as atividades essenciais, que deixem o local de trabalho para que trabalhem além do horário, dobrem ou tripliquem a jornada para garantir o funcionamento da empresa, embaraço à realização de assembleias, ameaça física, transferências de estabelecimento com a mudança de cidade, o suborno aos dirigentes grevistas para persuadir seus pares a cessarem o movimento, dentre outros.

Caracterizada a conduta antigrevista, restará a busca no poder judiciário pela reparação, que poderá ser por meio de tutelas de obrigações de fazer, ou não fazer, e de ações de indenização por danos morais e materiais ou quaisquer outras tutelas e provimentos hábeis a fazer cessar a conduta antigrevista.

No tocante às obrigações de fazer poderia se exemplificar com a condenação do empregador ou tomador de serviços, autor das condutas antigrevistas, de desmentir em jornal de grande circulação notícia anteriormente veiculada sobre a ilicitude da greve.

Mais fácil seriam as condenações de obrigação de não fazer, que se traduziriam na cessação ou proibição de realização de qualquer conduta que o empregador estiver praticando ou na iminência de praticá-la diante do livre exercício lícito do direito de greve. Tais condenações nas obrigações de não fazer são de extrema importância, haja vista que por meio delas se garante a força do movimento paredista e até mesmo a continuidade do direito de greve, não podendo se dar respaldo a qualquer violação do mesmo, sob pena desse direito sucumbir ante o poder que o empregador exerce em relação à greve.

Por fim, a reparação dos danos causados pelas condutas antigrevistas poderá se efetivar mediante indenizações por danos materiais e morais. 
Indenização por danos materiais será devida sempre que o trabalhador ou sua agremiação comprovarem que pelas condutas antigrevistas do empregador/tomador ocorreram prejuízos certos e, portanto, merecem ser indenizados pelo dano. Igualmente poderá ocorrer a indenização por dano moral, sendo este presumido, pois sempre que houver uma conduta antigrevista por parte do empregador o prejuízo moral para o trabalhador ou para sua agremiação será presumido, uma vez que tais condutas abalam o livre exercício do direito de greve e a credibilidade do movimento.

É verdade ainda que não se pode apenas falar em caracterização e reparação das condutas antigrevistas sem mencionar o mais importante, que seria sua prevenção no sentido de se garantir a plenitude do exercício do direito de greve. Com a prevenção de tais atos, o movimento grevista torna-se mais forte e sólido, apto a realizar seu escopo de pressão sobre o empregador ou tomador de serviços, para a consecução dos direitos buscados pela categoria, sejam de ordem salarial ou de melhoria nas condições de trabalho.

Por excelência, a prevenção tende a impedir que a conduta antigrevista chegue a se efetivar. Nas palavras de Barros (1999, p. 3) dissertando sobre as condutas antissindicais e por analogia utilizando para as condutas antigrevistas, o ato de prevenção "mais divulgado é aquele que condiciona a validade do ato à comunicação ou autorização prévia de determinado órgão, que poderá ser judicial, administrativa, sindical ou conselho de empresa”.

Nesse sentido a prevenção poderá se efetivar por meio de órgão judicial, administrativo ou até mesmo sindical. Não se pode perder de vista, ainda, a necessidade de o legislador inserir na lei de greve mecanismos de proteção contra as condutas antigrevistas, como um direito do trabalhador à sua livre adesão ao movimento paredista. Ao que parece, este seria o melhor e de maior alcance mecanismo de prevenção das condutas antigrevistas. 
Como se daria então a atuação judicial no combate às condutas antigrevistas, pois pelo que se constata esta é a medida, das anteriormente mencionadas, mais utilizada atualmente? Como defendido acima, a atuação judicial pelo princípio da inafastabilidade da jurisdição, artigo $5^{\circ} \mathrm{XXXV}$ da CR poderá atuar na forma de tutelas de obrigação de fazer e não fazer, de indenizações por danos morais e materiais, por reparações diversas das mencionadas, por tutelas de urgência em liminares de reintegração de trabalhadores, nas ações declaratórias, consistente na declaração, pelos tribunais, da legalidade do movimento, dentre outras tantas espécies de tutela que o caso concreto necessitar.

Exemplo típico de reintegração no emprego é o descrito no artigo 659, X da CLT, que garante a reintegração no emprego, por medida liminar, do empregado dirigente sindical afastado, suspenso ou dispensado pelo empregador. Apesar de se tratar tão somente do dirigente sindical e se referir às Juntas de Conciliação e Julgamento, extintas pela EC 24/99, o juiz poderá, pelo seu poder geral de cautela, reintegrar o trabalhador, que foi suspenso, afastado ou dispensado por ilegal ato antigrevista, mesmo não sendo ele dirigente do movimento paredista.

\subsection{O dano moral coletivo em decorrência das condutas antigrevistas}

Uma vez ocorrida qualquer conduta antigrevista caberá, como anteriormente mencionado, reparação na qualidade de indenização pelo dano moral coletivo.

Disciplina a Constituição da República em seu artigo $5^{\circ}$, incisos V e X, que fica assegurada a indenização por dano material e também moral pela violação de direito. 
A conduta antigrevista é um ato que causa um prejuízo material e até mesmo moral àquele que é agente passivo da conduta, ou seja, o trabalhador no seu livre direito fundamental de greve e o sindicato como viabilizador do movimento. Mais ainda o causará na qualidade de agente coletivo, vale dizer, o prejuízo que esta conduta causará à agremiação sindical e ao movimento paredista, enfraquecendo-o e podendo levá-lo a se tornar inócuo.

Nesse sentido, manifesta-se Barros acerca das condutas antissindicais que se adéquam perfeitamente à indenização pelo dano moral pelas condutas antigrevistas:

O dano daí advindo deve ser compensado em função da lesão a um bem extrapatrimonial. Essa tutela reparadora, a par de seu caráter compensador, visa ainda restituir a confiança ou credibilidade da ação sindical e devolver ao sindicato as armas e os instrumentos de tutela de seus direitos, dissuadindo o agente da conduta sindical a reincidir no comportamento lesivo (Barros, 1999, p. 3).

Como bem observado pela autora, a indenização pelo dano moral, mais do que a compensação monetária, servirá de sentido pedagógico para que outros não pratiquem a mesma conduta, bem como realizará um papel que se poderia chamar de função psicológica, ou seja, uma condenação neste sentido "levantará a autoestima" do movimento, que fortalecido poderá lutar pelos direitos da classe, bem como ainda dará confiança e credibilidade aos sindicatos profissionais e aos diversos movimentos paredistas.

O dano moral perpetrado por meio de tais condutas já é presumido, pois sem dúvida uma conduta antigrevista, seja em qual modalidade que se efetive, causará um prejuízo ao movimento paredista, enfraquecendo-o ou até mesmo desestimulando-o a ponto de inviabilizá-lo.

Acerca do dano moral manifesta-se Venosa: 
Será moral o dano que ocasiona um distúrbio anormal na vida do indivíduo; uma inconveniência de comportamento, ou como definimos um desconforto, um desconforto comportamental a ser examinado em cada caso. Ao se analisar o dano moral, o juiz se volta para a sintomatologia do sofrimento, a qual se não pode ser valorada por terceiro, deve no caso, ser quantificada economicamente.

Acrescentamos que o dano psíquico é modalidade inserida na categoria de danos morais, para efeitos de indenização. $\mathrm{O}$ dano psicológico pressupõe modificação de personalidade, com sintomas palpáveis, inibições, depressões, bloqueios, etc. ... o dano moral, em sentido lato, abrange não somente os danos psicológicos; não se traduz unicamente por uma variação psíquica, mas também pela dor e pelo procedimento moral, que não aflora perceptivelmente em outro sintoma. A dor moral insere-se no amplo campo da teoria dos valores. Desse modo, o dano moral é indenizável, ainda que não resulte em alterações psíquicas. Como enfatizamos, o desconforto anormal decorrente de conduta do ofensor é indenizável (Venosa, 2003, p. 34-35).

Como se observa da definição do autor, apesar de se tratar de uma definição voltada para o ser individual, mas que se poderá utilizá-la para o ente coletivo, o dano moral causa um transtorno, um desconforto anormal no movimento paredista, que poderá resultar em enfraquecimento psicológico nos dirigentes da paralisação e nos seus pares, que repercutirá no movimento como um todo.

É de se observar que, não obstante a conduta antigrevista seja direcionada a um trabalhador de forma individual ou a um dirigente, o dano será coletivo, ou seja, para todo o movimento do ser coletivo, o sindicato profissional. 
Nesse sentido, o dano moral será coletivo e a reparação, da mesma forma, deverá ser coletiva, revertendo se possível em favor do movimento grevista, se ainda existente ou em favor do sindicato profissional respectivo.

No primeiro caso, apesar de ser quase impossível, na prática seria a verdadeira concretização da justiça, pois a indenização viria para reparar o dano cometido pela conduta antigrevista, uma vez que os valores amealhados poderiam até mesmo ser utilizados como fundos para divulgação do movimento, deixando-o mais fortalecido monetariamente e psicologicamente por meio da recomposição judicial do dano suportado.

Nesta linha, como se trata de dano moral coletivo, interessante analisar a quem é atribuída a legitimidade para pleitear a reparação e como quantificar esta reparação.

O sindicato, por excelência, nos termos do artigo $9^{\circ}$ III da CR seria o legitimado para a defesa dos direitos coletivos e, por conseguinte, propor a mencionada ação. Impende destacar que na falta dos sindicatos, as respectivas federações ou confederações, e atualmente as centrais sindicais, seriam legitimadas ativas para acessarem o judiciário na busca da tutela do direito coletivo. Importante destacar ainda que se a categoria não tiver qualquer organização sindical, por exemplo, se se tratar de trabalhadores dispersos, sem vínculo de emprego, a legitimidade deverá ser conferida à comissão de negociação (grupo ocasional) eleita pela assembleia geral para o fim negocial e do movimento paredista.

O Ministério Público do Trabalho nos termos dos artigos 127 e 129 da Constituição de 1988 e da Lei Complementar 75/93, como defensor dos direitos sociais e individuais indisponíveis, outrossim, está legitimado para pleitear a indenização pelo dano moral coletivo. 
Nos termos ainda da Lei 7.347/85 (Lei da Ação Civil Pública) a Defensoria Pública estaria igualmente legitimada a propor tal ação coletiva. Na prática, contudo, isso não acontece, trata-se aqui de um problema de ordem institucional e pragmática, pois não há ainda no Brasil uma Defensoria Pública do Trabalho institucionalizada e mesmo que houvesse a prática demonstra que o Ministério Público e, principalmente os sindicatos têm realizado este papel de forma razoavelmente satisfatória.

No que respeita à quantificação do dano moral pela lesão coletiva de direitos, aflora a mesma discussão e dificuldade quanto à sua valoração na seara individual.

É bem verdade que a indenização pelo dano causado à moral do agente não irá sanar sua dor, todavia o dano moral deve ter em si um caráter dúplice, qual seja, o de trazer um lenitivo a fim de amenizar a dor moral sofrida pela vítima, bem como o caráter educativo, com o fito de que o agente ofensor não volte a reincidir em sua conduta.

É neste dualismo que se põe a quantificação do dano moral também na seara da reparação coletiva. Importa levar em conta que a reparação pelo dano moral coletivo deve trazer uma amenização da lesão aos direitos coletivos da classe, bem como na reparação coletiva deve ficar mais evidenciado o caráter pedagógico da condenação, pois uma penalidade por conduta antigrevista servirá como escopo educativo para que diversos outros empregadores e tomadores de serviço naquela conduta não incidam.

Assim, por se tratar de uma lesão ao interesse de diversos trabalhadores, ao contrário do dano moral individual, que pelo próprio nome refere-se a um só indivíduo ou alguns, o dano moral coletivo interessa a uma determinada classe de trabalhadores muito maior que o indivíduo, e, portanto, deve ser quantificado em valores muito mais elevados que o individual, sempre observando, outrossim, a capacidade econômico-financeira do ofensor e de modo que não sirva de enriquecimento aos lesados. 
Dessa forma, é perfeitamente cabível a ação de indenização por dano moral coletivo daquele sindicato ou comissão de negociação, contra o empregador e tomador de serviços por lesão ao direito coletivo fundamental de greve, assegurado legal e constitucionalmente, que foi ferido pelas condutas antigrevistas do empregador.

\section{CONSIDERAÇÕES FINAIS}

Pelo exposto, observa-se que o direito de greve no Brasil, apesar de atualmente estar garantido pela Constituição da República de 1988 como direito fundamental, nem sempre foi desta forma, muito se teve de lutar, luta esta que se travou principalmente dentro do movimento sindical, ainda que este, em quase toda sua história, esteve submetido ao poder estatal.

Com a Constituição de 1988 o direito de greve foi elevado à categoria de direito fundamental do homem, entendido como um ser coletivo tão importante como os direitos fundamentais de ordem individual.

Não obstante, ainda que seja um direito fundamental garantido pela CR em seu artigo $9^{\circ}$ e pela legislação infraconstitucional, lei 7.783/89, muitas condutas do empregador/tomador de serviços diante do movimento paredista se traduzem em embaraço ou total inviabilidade do direito de greve, atos estes denominados de condutas antigrevistas.

Tais condutas poderão se efetivar das mais diversas formas, tais como ameaça de demissão, efetivação de demissões coletivas, principalmente de líderes grevistas, dentre outras.

Nesse sentido, caracterizada uma conduta que se contrapõe ao direito fundamental de greve, cabe à parte lesada recorrer ao judiciário para buscar uma tutela para cessar o assédio ao exercício deste direito fundamental, que poderá se traduzir em uma obrigação de fazer ou não fazer, 
bem como mediante liminares de reintegração de grevistas aos postos de trabalho. Além disso, importante frisar a possibilidade de se buscar uma tutela na modalidade de indenização por dano material e moral.

O dano moral coletivo poderá ser ainda pleiteado pela categoria sindical, pelo Ministério Público do Trabalho ou Defensoria Pública perante a Justiça do Trabalho.

O judiciário poderá sempre ser acionado quando se vislumbrar uma conduta antigrevista diante de um movimento paredista. Primeiramente, deve-se buscar a prevenção destas condutas, o que se torna na prática às vezes um pouco difícil de se realizar pelo judiciário, no entanto, no momento em que estas ocorrem a tutela jurisdicional poderá ser buscada no sentido de fazer cessar estas condutas, e por fim, quando efetivadas e sem a possibilidade de prevenção e cessação, poderá se buscar uma indenização pelos danos ocorridos.

Importante destacar ainda que as condutas antigrevistas, como abuso de direito, deveriam ser normatizadas na lei de greve ou em legislação especial para garantia do livre direito de greve, dando-lhe ainda mais eficácia.

De todo o analisado acima parece ter este estudo alcançado seu objetivo. Restou demonstrado que atualmente o direito de greve é um direito fundamental constante da CR e da legislação infraconstitucional. Sendo todas as condutas do empregador e do tomador de serviços que criem embaraços ou inviabilize o livre gozo deste direito fundamental, caracterizadas como condutas antigrevistas.

Observa-se ainda que o poder judiciário, pelo princípio da inafastabilidade da jurisdição, sempre poderá ser acionado para prevenir, cessar, proibir ou reparar as condutas antigrevistas por meio de diversas formas de tutela, notadamente as ações de dano moral coletivo. 
Diante do exposto, conclui-se que não obstante o direito de greve estar assegurado constitucionalmente, ainda há um sentimento arraigado de que a greve é um delito, um mal para a sociedade que precisa ser combatido, o que se faz muitas vezes por condutas antigrevistas do empregador/tomador de serviços, que obstaculiza o direito de greve e por vezes até mesmo o inviabiliza. Nesse contexto, tais condutas devem ser combatidas pelo poder judiciário sem perder de vista a necessidade de a legislação de greve assegurar em seu texto o combate às condutas antigrevistas do empregador e tomador de serviços que afetam o livre exercício do direito fundamental de greve e, por conseguinte, toda a sociedade, tão dependente hoje dos serviços de uma ou outra empresa.

\section{REFERÊNCIAS}

BARROS, Alice Monteiro de. Condutas anti-sindicais - procedimento. Natal, set. 1999. Disponível em: <www.mg.trt.gov.br/escola/download/revista/ rev_59/Alice_Barros.pdf>. Acesso em: 06 jan. 2011.

BARROSO, Luís Roberto. O direito constitucional e a efetividade de suas normas. 6. ed. Rio de Janeiro: Renovar, 2002.

BRASIL. Constituição. Constituição da República Federativa do Brasil, de 5 de outubro de 1988. Diário Oficial da União, Brasília/DF, 05 out. 1988.

. Lei $\mathrm{n}^{\mathrm{o}} 7.783$, de 28 de junho de 1989. Dispõe sobre o exercício do direito de greve, define as atividades essenciais, regula o atendimento das necessidades inadiáveis da comunidade, e dá outras providências. Diário Oficial da União, Brasília/DF, 29 jun. 1989.

. Lei $\mathrm{n}^{\circ} 10.406$, de 11 de janeiro de 2002. Institui o Código Civil. Diário Oficial da União, Brasília/DF, 11 jan. 2002. 
. Supremo Tribunal Federal. Mandado de Injunção $\mathrm{n}^{0}$ 712- PA. Relator: Ministro Eros Grau. Diário de Justiça Eletrônico, Brasília/DF, 25 out. 2007. Disponível em: <http://www. stf.jus.br/portal/processo/verProcessoAndamento.asp?numero=712\&classe $=$ MI\&origem $=$ AP\&recurso=0\&tipoJulgamen to $=\mathrm{M}>$. Acesso em: 07 jan. 2011.

CASTILHO, Santiago Pérez del. O direito de greve. São Paulo: LTr, 1994.

CESÁRIO, João Humberto. O direito constitucional fundamental de greve e a função social da posse. Um novo olhar sobre os interditos possessórios na Justiça do Trabalho brasileira Jus Navigandi, Teresina, ano 12, n. 1.604, 22 nov. 2007. Disponível em: <http://jus.com.br/artigos/10683>. Acesso em: 06 jan. 2011.

DELGADO, Maurício Godinho. Curso de direito do trabalho. 5. ed. São Paulo: LTr, 2006.

MARTINS, Sergio Pinto. Direito do trabalho. 23. ed. São Paulo: Atlas, 2007. MELO, Raimundo Simão de. A greve no direito brasileiro. 2. ed. São Paulo: LTr, 2009.

NASCIMENTO, Amauri Mascaro do. Comentários à lei de greve. São Paulo: LTr, 1989.

Curso de direito do trabalho. 17. ed. São Paulo: Saraiva, 2001.

ORGANIZAÇÃO INTERNACIONAL DO TRABALHO. OIT. Comitê de Liberdade Sindical e Comissão de Peritos. Normas internacionais do trabalho. Lisboa, [s.d.]. Disponível em: <http://www.ilo.org/public/portugue/region/ eurpro/lisbon/html/portugal_visita_guiada_03b_pt.htm>. Acesso em: 24 jan. 2014a.

. Convenção $n^{0}$ 98: direito de sindicalização e negociação coletiva. Aprovada pelo Decreto Legislativo do Congresso Nacional $n^{\circ} 49$, de 27/08/1952, e Decreto $\mathrm{n}^{\circ}$ 33.196, de 29/06/1953, com vigência nacional em 18 de novembro de 1953. Disponível em: <http://www.oitbrasil.org.br/node/465>. Acesso em: 23 jan. 2014b. 
RODRIGUES, Sarah. Eletricitários da Cemig completam 16 dias de greve. Gazeta do Oeste, Divinópolis/MG, 20 a 22 nov. 2010. Caderno Cidades, p. 07. SANTOS, Enoque Ribeiro dos. Internacionalização dos direitos humanos trabalhistas: $o$ advento da dimensão objetiva e subjetiva dos direitos fundamentais. Revista LTr: Legislação do Trabalho, São Paulo, v. 72, n. 3, p. 277-284, 2008.

SARLET, Ingo Wolfgang. A eficácia dos direitos fundamentais. 6. ed. Porto Alegre: Livraria do Advogado, 2006.

SILVA, José Afonso da. Curso de direito constitucional positivo. 35. ed. São Paulo: Malheiros, 2012.

. Curso de direito constitucional positivo. 5. ed. São Paulo: Revista dos Tribunais, 1989.

SUSSEKIND, Arnaldo et al. Instituições de direito do trabalho. 22. ed. São Paulo: LTr, 2005. V. II.

URIARTE, Oscar Ermida. A proteção contra os atos anti-sindicais. Tradução Irany Ferrari. São Paulo: LTr, 1989.

VENOSA, Silvio de Salvo. Direito civil. 3. ed. São Paulo: Atlas, 2003. v. 4.

Recebido em: $22 / 7 / 2013$

Revisões requeridas em: 22/1/14

Aceito em: $11 / 2 / 2014$ 